\title{
Role of nebulized glycopyrrolate in the treatment of chronic obstructive pulmonary disease
}

This article was published in the following Dove Press journal:

Drug Design, Development and Therapy

15 November 2017

Number of times this article has been viewed

\section{Pierachille Santus' \\ Dejan Radovanovic' \\ Andrea Cristiano' \\ Vincenzo Valenti \\ Maurizio Rizzi'}

'Department of Biomedical and Clinical Sciences (DIBIC), University of Milan, Division of Respiratory Diseases, "L. Sacco" Hospital, ASST Fatebenefratelli Sacco, Milan, Italy; 2Department of Health Bioscience, University of Milan - Respiratory Unit, Policlinico di San Donato, IRCCS San Donato Milanese, Milan, Italy
Correspondence: Pierachille Santus Department of Biomedical and Clinical Sciences (DIBIC), University of Milan, Division of Respiratory Diseases, "L. Sacco" Hospital, Via G.B. Grassi 74, 20157 Milan, Italy

Tel +3923904280I

$\mathrm{Fax}+39239042473$

Email pierachille.santus@unimi.it

\begin{abstract}
In the upcoming years, the proportion of elderly patients with chronic obstructive pulmonary disease (COPD) will increase, according to the progressively aging population and the increased efficacy of the pharmacological treatments, especially considering the management of chronic comorbidities. The issue to prescribe an appropriate inhalation therapy to COPD patients with significant handling or coordination difficulties represents a common clinical experience; in the latter case, the choice of an inadequate inhalation device may jeopardize the adherence to the treatment and eventually lead to its ineffectiveness. Treatment options that do not require particular timing for coordination between activation and/or inhalation or require high flow thresholds to be activated should represent the best treatment option for these patients. Nebulized bronchodilators, usually used only in acute conditions such as COPD exacerbations, could fulfill this gap, enabling an adequate drug administration during tidal breathing and without the need for patients' cooperation. However, so far, only short-acting muscarinic antagonists have been available for nebulization. Recently, a nebulized formulation of the inhaled long-acting muscarinic antagonist glycopyrrolate, delivered by means of a novel proprietary vibrating mesh nebulizer closed system (SUN-101/eFlow ${ }^{\circledR}$ ), has progressed to Phase III trials and is currently in late-stage development as an option for maintenance treatment in COPD. The present critical review describes the current knowledge about the novel nebulizer technology, the efficacy, safety, and critical role of nebulized glycopyrrolate in patients with COPD. To this end, PubMed, ClinicalTrials.gov, Embase, and Cochrane Library have been searched for relevant papers. According to the available results, the efficacy and tolerability profile of nebulized glycopyrrolate may represent a valuable and dynamic treatment option for the chronic pharmacological management of patients with COPD.
\end{abstract}

Keywords: glycopyrrolate, glycopyrronium, nebulizer, COPD, antimuscarinic, device

\section{Introduction}

Chronic obstructive pulmonary disease (COPD) is characterized by not fully reversible airflow obstruction due to structural derangement of the airways, sustained by an inflammatory response secondary to inhalation of noxious particles, mainly represented by cigarette smoke and air pollutants. ${ }^{1}$ COPD represents an increasing social and health care problem, and a leading cause of disability. In current projections, mortality due to COPD will eventually increase by 2030 to become the third most common cause of death worldwide. ${ }^{2}$ In COPD, both chronic bronchitis and emphysema can be present with different intensities and are responsible for airway narrowing, mucus hyper-secretion, loss of small conducting airways, and lung elastic recoil. ${ }^{3}$ Starting from the peripheral airways, which represent the site of the initial damage, these anatomic changes eventually lead to expiratory airflow limitation, air trapping, dynamic hyperinflation, increased closing volume, and 
ventilation-perfusion mismatch. ${ }^{4-6}$ Long-acting muscarinic antagonists (LAMAs), such as tiotropium, aclidinium, glycopyrronium, and umeclidinium, and long-acting $\beta 2$ agonists (LABAs), such as indacaterol, formoterol, salmeterol, and olodaterol, are able to reduce hyperinflation ${ }^{7}$ and the extent of airway closure, ${ }^{8}$ improving symptoms and exercise tolerance, ${ }^{9}$ and thus represent the cornerstone of the long-term pharmacological treatment in COPD. Although inhaled therapy has the advantage to be administered directly to the site of action, the process interposed between the actuation of the device and the drug deposition in lung periphery relies on numerous variables, namely the drug formulation, patients' inhalation technique, and lung mechanics. ${ }^{10}$ So far, the most widespread hand-held inhalers' devices are represented by dry powder inhalers (DPIs), pressurized metered dose inhalers (pMDIs), and soft mist inhalers (SMIs), while nebulizers are often left for the treatment of acute conditions such as COPD exacerbations or in patients with extremely limited self-sufficiency. ${ }^{11}$ Although effective, technologically advanced and portable, the use of handheld devices has always been affected by numerous major mistakes that lead to an incorrect inhalation technique and eventually to the lack of treatment efficacy, ${ }^{10}$ especially in older patients with COPD, with a severe disease and multiple comorbidities. ${ }^{10}$ In the latter group of patients, drug delivery via nebulization may provide an effective alternative, since an optimal dose can be delivered during tidal breathing, regardless of disease severity or associated comorbidities, thus overcoming the need for coordination, specific handling and inspiratory maneuvers. ${ }^{12}$

The present critical review will be focused on the nebulized delivery technology, developmental phases, efficacy and safety of nebulized glycopyrrolate (nebulized glycopyrronium bromide [GBn]) in patients with COPD. Medline, Embase, Cochrane Library, and ClinicalTrials.gov were searched for relevant full papers and conference abstracts up to August 2017. Only manuscripts in English language were considered.

\section{Management issues in COPD treatment}

The peculiarity of the pharmacology of the respiratory system is represented by the possibility to grant drug delivery directly to the desired site of action, allowing to bypass the majority of the intermediate metabolic steps usually inevitable for other administration routes. ${ }^{13,14}$ However, the efficacious access to the lung is jeopardized by complex variables that range from drug formulation and posology to the pathophysiology and stage of the disease. In this view, adherence becomes crucial for treatment efficacy. In clinical trials, adherence to inhaled treatments is usually $>80 \%,{ }^{15}$ a result that does not usually reflect the real life context, in which adherence can be as low as $10 \% .^{16,17}$ Reduced adherence does not only impact the daily clinical management of patients with COPD but also increases the frequency of exacerbations, the number of hospitalizations, and emergency department visits, thus negatively affecting health care costs. ${ }^{18}$

The device used to deliver the inhaled drug represents a fundamental step for the clinical decision process and may be as important as the choice of the drug itself. The inhalation devices more commonly prescribed are represented by pMDIs, DPIs, SMIs, and nebulizers. Despite a long-standing debate, there is no consensus on how to match patient requirements with criteria for selecting an alternative inhaler device. Rather than insisting with training a patient with a specific inhaler, it would be more appropriate to match the device with the needs and the skills of the patient. ${ }^{10}$ Most of the inhalation devices currently available on the market have a comparable efficacy, provided they are used appropriately. ${ }^{11,19-21}$ During drug administration, up to $75 \%$ of patients with COPD do not receive an optimal dose of the inhaled drug, mainly because of poor coordination or inhalation techniques. ${ }^{22,23}$

For pMDIs, the most common administration errors are represented by the patient's poor coordination between the device activation and drug inhalation or by a short inhalation time. During DPIs' use, patients are often unable to obtain a sufficient inspiratory peak flow necessary get the resistance required to activate the drug and dissociate the carrier from the active molecule; moreover, common mistakes regard dose preparation and exhalation through the device prior to inhalation. ${ }^{24-27}$ Even the use of SMI requires an accurate priming and breathing technique, ${ }^{28}$ although the timing for inspiration and the required inspiratory flow are respectively longer and lower compared to pMDIs, since the delivered aerosol lasts three times longer than in pMDIs. ${ }^{25}$ DPIs are often sensitive to humidity, which can reduce the delivered dose, while SMIs and pMDIs, when left unused for some time, must be re-primed. ${ }^{29}$ Advantages and disadvantage of the devices currently available on the market are summarized in Table 1.

Generally, patients that commit errors during inhalatory therapy hiring, tend to be older, more debilitated and to have a severe disease. In elderly patients, unintentional nonadherence to inhalation therapy often comes from cognitive impairment, hearing or visual loss, and other physical disabilities, such as arthritis and tremors resulting in poor coordination, which significantly affect their ability to 
Table I Advantages and disadvantages of inhalation devices

\begin{tabular}{|c|c|c|}
\hline Device type & Advantages & Disadvantages \\
\hline PMDI & $\begin{array}{l}\text { - Portable } \\
\text { - Does not require preparation } \\
\text { - No drug contamination risk } \\
\text { - High reproducibility for each actuation } \\
\text { - Multidose } \\
\text { - High number of drugs to choose }\end{array}$ & $\begin{array}{l}\text { - Needs coordination between inspiration and dose actuation } \\
\text { - High oropharyngeal deposition } \\
\text { - Does not always indicate the number of doses left } \\
\text { - Contain propellants } \\
\text { - Need to be re-primed after no use }\end{array}$ \\
\hline Ultrafine pMDI & $\begin{array}{l}\text { - Portable } \\
\text { - Does not require preparation } \\
\text { - No drug contamination risk } \\
\text { - High reproducibility for each actuation } \\
\text { - Multidose } \\
\text { - High lung deposition and minor } \\
\text { oropharyngeal deposition }\end{array}$ & $\begin{array}{l}\text { - Few drugs to choose } \\
\text { - Needs coordination between inspiration and dose actuation } \\
\text { - Does not always indicate the number of doses left } \\
\text { - Fast expiration if containing formoterol } \\
\text { - Needs to be re-primed after no use }\end{array}$ \\
\hline Breath-actuated pMDI & $\begin{array}{l}\text { - Useful when coordination is lacking } \\
\text { - Useful in older age } \\
\text { - Does not require spacers }\end{array}$ & - Needs adequate inhalation effort \\
\hline DPI & $\begin{array}{l}\text { - No coordination required } \\
\text { - No propellant needed } \\
\text { - Remaining dose counters } \\
\text { - Portable } \\
\text { - Usually multidose } \\
\text { - Short administration time }\end{array}$ & $\begin{array}{l}\text { - Usually requires more steps to prepare the drug prior to inhalation } \\
\text { - Some are single-dose } \\
\text { - Needs adequate inhalation effort } \\
\text { - Higher oropharyngeal deposition } \\
\text { - Usually more expensive than pMDls } \\
\text { - Humidity can reduce the released dose } \\
\text { - Device declivity for a correct loading dose }\end{array}$ \\
\hline SMI & $\begin{array}{l}\text { - Easy to use } \\
\text { - Portable } \\
\text { - Multidose } \\
\text { - No propellant needed } \\
\text { - Higher actuation duration limiting the effects } \\
\text { of poor coordination activation/inhalation }\end{array}$ & $\begin{array}{l}\text { - Needs careful preparation at the first use } \\
\text { - Multiple steps involved } \\
\text { - Needs to be re-primed after no use }\end{array}$ \\
\hline Jet nebulizer & $\begin{array}{l}\text { - Easy to use } \\
\text { - No need for coordination } \\
\text { - Adapt for every age (even }<4 \text { years) } \\
\text { - Available for oxygen enrichment } \\
\text { - Contemporaneous use of different drugs } \\
\text { - No propellant needed } \\
\text { - Can be used by bedridden patients }\end{array}$ & $\begin{array}{l}\text { - Cumbersome } \\
\text { - Noisy } \\
\text { - High treatment time } \\
\text { - Possibility of microbial contamination } \\
\text { - Needs cleaning and periodic maintenance } \\
\text { - Needs electricity } \\
\text { - Uncertainty of effective dose delivered to the lung }\end{array}$ \\
\hline $\begin{array}{l}\text { Ultrasonic wave } \\
\text { nebulizer }\end{array}$ & $\begin{array}{l}\text { - Easy to use Requires minimal cognitive ability } \\
\text { - Lightweight } \\
\text { - Silent } \\
\text { - No need for coordination } \\
\text { - Adapt for every age (even }<4 \text { years) } \\
\text { - Available for oxygen enrichment } \\
\text { - Contemporaneous use of different drugs } \\
\text { - No propellant needed } \\
\text { - Can be used by bedridden patients }\end{array}$ & $\begin{array}{l}\text { - Possible drug heat degradation } \\
\text { - Too much liquid waste } \\
\text { - High treatment time } \\
\text { - Possibility of microbial contamination } \\
\text { - Needs cleaning and periodic maintenance } \\
\text { - Needs electricity } \\
\text { - Uncertainty of effective dose delivered to the lung }\end{array}$ \\
\hline Ultrasonic VMT & $\begin{array}{l}\text { Same advantages as ultrasonic nebulizers } \\
\text { - Shorter treatment time } \\
\text { - High efficiency and less waste } \\
\text { - No drug degradation } \\
\text { - Battery powered } \\
\text { - Easy to clean, disinfect and autoclave } \\
\text { - Display delivers feedback during inhalation }\end{array}$ & $\begin{array}{l}\text { - Higher price } \\
\text { - Needs cleaning after every use } \\
\text { - Not available for contemporaneous use of different drugs } \\
\text { - May not readily aerosolize drug suspensions }\end{array}$ \\
\hline
\end{tabular}

Abbreviations: DPI, dry powder inhaler; pMDI, pressurized metered dose inhaler; SMI, soft mist inhaler; VMT, vibrating mesh technology.

understand and follow the suggested treatment. Complex pharmacological regimens are also secondary to multiple chronic comorbidities, representing a major risk factor for impaired adherence. ${ }^{25}$

\section{Glycopyrrolate by nebulizer}

Taking into account the aging population and the projected increase in the prevalence of respiratory tract diseases, patients with COPD will become older, and treatment options 
that do not require an optimal coordination for activation/ inhalation or require a flow threshold to be activated will become the preferable treatment option.

To date, nebulized muscarinic antagonists are limited to short-acting formulations (SAMAs), while $\beta$-agonists are available both as short-acting (SABAs) and as long-acting formulations (aformoterol tartrate), the latter approved only in the USA. SAMA and SABA, in addition to being the treatment choice in acute conditions, are also often suggested for maintenance treatment in selected COPD patients. However, to maintain an optimal bronchodilation coverage, three or four doses per day are needed when SAMA and SABA are delivered via a general purpose jet nebulizer. The latter are usually bulky, characterized by limited portability and with dispensing times of 10-15 minutes per dose, aspects that likely affect patients' compliance. In view of the aforementioned limitations, the lack of long-acting molecules that would reduce the daily posology and a shorter delivery time appear desirable. ${ }^{30}$

The GOLD document recommends nebulizers to be used in specific populations, such as patients with inspiratory flow rates as low as $<30 \mathrm{~L} / \mathrm{s}$ or patients with poor hand-eye coordination. ${ }^{1}$ Furthermore, the benefits of nebulizer treatment over DPI and MDI formulations should be evaluated symptomatically and the treatment should be continued as long as similar benefits are not achievable by simpler, cheaper, and more portable alternatives. Indeed, recent surveys reported both patients and their caregivers to be increasingly satisfied with nebulized drug delivery, in terms of symptom relief, ease to use, and improved quality of life..$^{10,11,31}$

Nebulizers can convert a liquid into aerosol droplets suitable for patient inhalation. Currently, the technologies available are mainly represented by air-jet nebulizers, the most widely used, and ultrasonic nebulizers. There are also two pysicochemical categories of drugs available for nebulization: solutions and suspensions. Solutions contain a drug dissolved in saline or other liquids. Suspensions contain a drug that is not soluble in water or other respirable liquids but exist as a mixture of small drug particles suspended in liquid, which jeopardizes their presence in each droplet generated during the nebulization process. Conventional ultrasonic nebulizers cannot be used to administer suspensions. ${ }^{30}$

Due to their safety profile and to a better exacerbationpreventing effect compared to LABAs, ${ }^{32,33}$ LAMAs are usually the preferred starting therapy for COPD patients, but no nebulized LAMA is actually available on the market. As a part of the maintenance treatment of patients with COPD, in last years, glycopyrronium bromide (GB) has been developed and available as a single agent, in combination with LABAs, ${ }^{34-36}$ or in triple therapy in fixed dose combination with LABAs and inhaled corticosteroids (ICSs). ${ }^{37,38}$ The effects of GBn have been studied since 1984 in patients affected by asthma and since 1995 in patients with COPD..$^{39,40}$ Interestingly, probably due to its limits in administering time and portability, nebulization was the first to be studied, but the least to be proposed on the market. In the last years, several clinical trials have investigated a nebulized formulation of GBn delivered by a high efficiency nebulizer, which is currently awaiting for the US Food and Drug Administration (FDA) approval as maintenance therapy in COPD patients.

GBn has been investigated as a soluble molecule named EP-101 in 2015. ${ }^{41}$ Later on, under the name of SUN-101, it was part of the Glycopyrrolate for Obstructive Lung Disease via Electronic Nebulizer (GOLDEN) development program, consisting of a total of seven trials. ${ }^{42-48}$

GBn was studied to be delivered by the eFlow ${ }^{\circledR}$ Closed System (eFlow ${ }^{\circledR} \mathrm{CS}$ ) device (PARI Pharma GmbH, Starnberg, Germany). The latter is characterized by the possibility to deliver a wide range of drug volumes $(0.5-5 \mathrm{~mL})$ and dosages (0.001-1,000 mg). In addition, the hole sizes can be adjusted from just $<2 \mu \mathrm{m}$ upward, allowing this system to deliver drugs during consecutive breaths. The eFlow ${ }^{\circledR}$ is a vibrating mesh nebulizer, an evolution of 2005 ultrasonic wave nebulizers, in which a mesh/membrane with 1,000-7,000 laser-drilled holes vibrate at the top of the liquid reservoir, pressuring out a mist of very fine droplets through the holes. The latter technology appears to have solved some important issues existent with previous nebulizers, such as having too much liquid waste and undesired heating of the medical liquid. Portability for these devices is also enhanced by the battery-power and lightweight design. A disadvantage of vibrating mesh nebulizers consists of the little information concerning the ideal dose of the bronchodilator solution to be added to the nebulizer; consequently, the potential of over-dosing exists if the same dose for conventional jet nebulizers is used. To address this concern, a new generation of closed system mesh nebulizers has been conceived that will accept only the ampule containing the specific drug approved for use. ${ }^{49}$

In successive trials, a modified version of the eFlow ${ }^{\circledR}$ nebulizer was adopted: the eFlow ${ }^{\circledR} \mathrm{CS}$. The latter is a handheld, portable, battery-operated, electronic vibrating membrane nebulizer, modified from an FDA-cleared open-system device used to deliver cystic fibrosis medications. Like other vibrating mesh nebulizers, the $\mathrm{eFlow}^{\circledR}$ is virtually silent, 


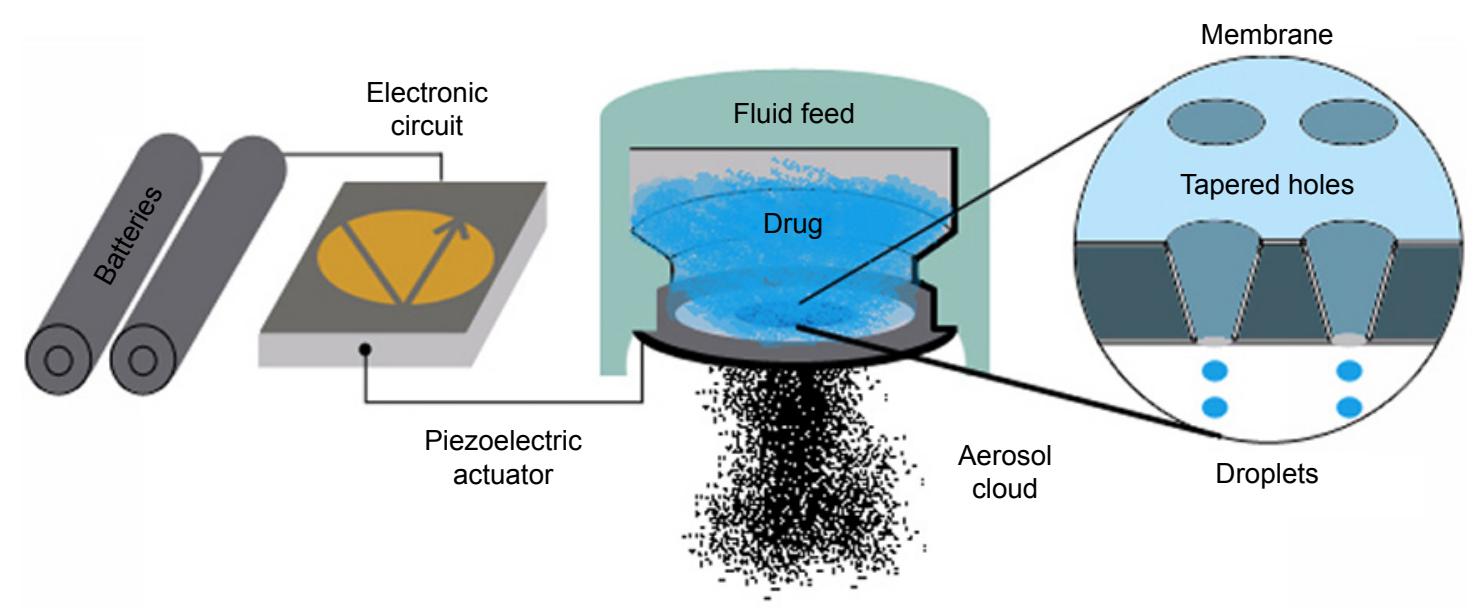

Figure I Simplified structure of the eFlow ${ }^{\circledast}$ (PARI Pharma GmbH, Starnberg, Germany) nebulizer.

designed to deliver the medication in two to three minutes during tidal breathing. It has been shown to improve patient compliance due to its comparatively short treatment time since it is more efficient than having a vibrating piezoelectric element at the bottom of the liquid reservoir (Figure 1). ${ }^{50}$ The most common jet nebulizers are usually cumbersome, not portable, noisy (up to $60 \mathrm{~dB}$ ) and require 10-15 minutes to deliver the drug. ${ }^{51}$

Fundamental for the destiny of an aerosolized particle is its aerodynamic diameter, determined by geometrical diameter, density, and form. ${ }^{52}$ Only particles with a diameter between 5 and $0.5 \mu \mathrm{m}$ can reach and stay in the lung: bigger particles impact on upper airways' mucosa, while smaller ones usually reach alveoli but are also exhaled away since they fail to lay on the epithelium. ${ }^{52,53}$ The mass median aerodynamic diameter (MMAD), geometric standard deviation (GSD), and fine particle fraction (FPF, $\%,<5 \mu \mathrm{m}$ ) of the eFlow ${ }^{\circledR}$ CS system have values independent of formulation strength. For both strengths tested, the mean MMAD was $3.7 \mu \mathrm{m}$, the mean GSD was 1.7 , and the mean FPF was $72 \%$. As expected in tidal breathing conditions, aerosol is expelled to waste during the exhalation phase. Compared to general purpose nebulizers, which can nebulize different drugs, to avoid incorrect dosing of the medication, the eFlow ${ }^{\circledR} \mathrm{CS}$ uses a unique ready-to-use unit-dose vial, designed to mitigate misuse and ensure dose uniformity. ${ }^{3,52,54}$ The device requires to be disassembled and cleaned after each use to prevent clogging of the mesh openings. At the time of this review, the eFlow $^{\circledR}$ system used for cystic fibrosis is being sold for $\$ 800-1,000 .^{51}$

Traditional nebulization route has some limits indeed, especially in regard to the output variation between different nebulizers of the same type. In fact, factors affecting nebulizer output are inextricably linked with those affecting particle size and nebulization time. ${ }^{55}$ Output can be diminished if the jet is blocked with dirt or drug crystals. Repeated uses may increase the diameter of the air orifice thus increasing the mean diameter of the droplets generated and reducing the air speed. This aging may be due to mechanical wear from the compressed air source or to excessive cleaning. Nebulizers designed to deliver small particles may have increased residual volume, decreasing drug output and increasing recirculation of the nebulizer solution, thus lengthening nebulization time. Increasing the volume fill improves drug output but lengthens nebulization time. Increasing driving gas flow rate may help, but for home use a higher performance compressor may be needed..$^{56}$ Another disadvantage is represented by the need of the end-user to load the medication prior to each administration. ${ }^{57}$

Despite some drawbacks associated with nebulizers, current evidence suggests that the efficacy of treatments administered to patients with moderate-to-severe COPD via nebulizers is similar to that observed with pMDIs and DPIs. ${ }^{20-23}$ Furthermore, for some patients, the use of both a nebulizer as maintenance therapy and a handheld inhaler as rescue medication may provide the best combination of efficacy and convenience.

\section{Pharmacology of glycopyrrolate via nebulizer Chemistry and pharmacokinetics}

Glycopyrronium, the active moiety of its bromide salt, also known as glycopyrrolate, is an antimuscarinic drug that was initially approved by the FDA for systemic administration for the reduction of sialorrhea due to preoperative stages, neuromuscular, and drug-related diseases ${ }^{58,59}$ and due to the 
property of reducing gastric secretions, as a treatment for peptic ulcer. ${ }^{60}$ It is a quaternary ammonium derivative - $(1,1-$ dimethylpyrrolidin-1-ium-3-yl) 2-cyclopentyl-2-hydroxy2-phenylacetatethat ${ }^{61}$ - with a peripheral effect similar to atropine. The chemical structure of GB is reported in Figure 2.

GB is rapidly absorbed into the systemic circulation after inhalation, $\approx 90 \%$ via lung and $\approx 10 \%$ via gastrointestinal absorption. ${ }^{62}$ The mean terminal elimination half-life $\left(t_{1 / 2}\right)$ of GB-DPI, is half that reported for GB-MDI (from 13 to 22 hours for a dose range of $25-200 \mu \mathrm{g}^{63}$ and from 6.3 to 9.6 hours for a dose range of 14.4-115.2 $\mu \mathrm{g}$ ), leaving open discussion on whether these pharmacokinetic features should be interpreted as a signal favoring the once daily (OD) or a bis in die (BID) administration. During the Phase II study by Leaker et $a{ }^{41}$ a formulation of GBn delivered by the eFlow $^{\circledR}$ nebulizer was rapidly absorbed with peak plasma concentrations within 15-30 minutes. There were only two measurable plasma GBn concentrations available with the $12.5 \mu \mathrm{g}$ dose. Therefore, $12.5 \mu \mathrm{g}$ was not included in the dose proportionality analysis. The elimination half-life $\left(t_{1 / 2}\right)$ of GBn was calculated for the 0-1 and 0-12 hours intervals. The median $t_{1 / 2}, 0-1$ hours ranged from 1.10 to 1.15 hours, and median $t_{1 / 2}, 0-12$ hours ranged from 2.30 to 7.45 hours, following administration of 50,100, 200, and $400 \mu \mathrm{g}$ of GB, respectively. ${ }^{41}$

\section{Metabolism and elimination}

$\mathrm{GB}$ is nonenzymatically hydrolyzed to form the major circulating metabolite, M9, which is a racemic carboxylic acid derivative, formed from the swallowed fraction of inhaled GB (Figure 2). ${ }^{62}$ In animal models, the primary biotransformation pathways for GB have been demonstrated to include the addition of one or two oxygen atoms to the cyclopentane and phenyl rings and dehydrogenation on the cyclopentane ring. ${ }^{64}$ Further hydrolysis of the ester linkage

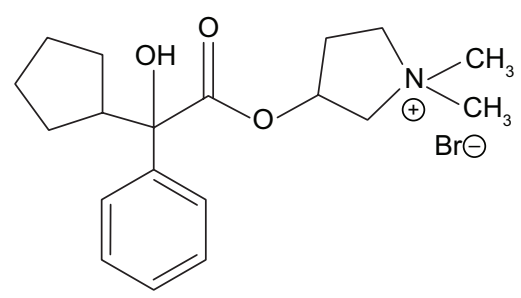

Glycopyrronium bromide

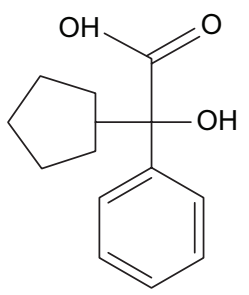

Metabolite M9
Figure 2 Chemical structure of glycopyrronium bromide (left) and its plasma metabolite M9 (right).

Note: M9 is formed through nonenzymatic hydrolysis of glycopyrronium bromide. forms the M9 metabolite. About $10 \%$ of systemic exposure is due to the swallowed drug, oral bioavailability of GB being 5\%. The metabolite M9 has a plasma concentration that is approximately the same as that of the parent drug after inhalation but not after intravenous administration. ${ }^{64}$ Biliary excretion contributes $\sim 5 \%$ to total clearance. GB also forms various mono and bis-hydroxylated metabolites in vitro. Glucuronide and sulfate conjugates of GB were recovered in urine of subjects receiving multiple dosages of inhaled drug. ${ }^{64}$ The most quantitatively important cytochrome that contributes to the metabolism of GB is CYP2D6. ${ }^{64}$

\section{Pharmacodynamics}

Muscarinic antagonists promote the relaxation of airway smooth muscle by blockade of the acetylcholine receptor. ${ }^{65}$ GB is a competitive muscarinic receptor antagonist that bronchodilates the airways by inhibiting acetylcholine induced bronchoconstriction in bronchial smooth muscle cells. ${ }^{66}$ The three main muscarinic receptors related with human lung bronchial dynamics are the $\mathrm{M}_{1}, \mathrm{M}_{2}$, and $\mathrm{M}_{3}$ receptors. $\mathrm{M}_{2}$ receptor protects against bronchoconstriction and its block may increase heart rate. ${ }^{36,66}$ The bronchoconstrictor effect of acetylcholine is mediated mainly through $\mathrm{M}_{3}$ receptors located on airway smooth muscle cells, whereas $M_{1}$ receptors enhance cholinergic reflexes. In contrast, $\mathrm{M}_{2}$ receptors on cholinergic nerve endings inhibit acetylcholine release, thus reducing bronchoconstriction, and should not be blocked. ${ }^{67}$ Mucus secretion is largely mediated by $M_{3}$ receptors and $M_{3}$ receptor blockade may also reduce mucus hypersecretion. ${ }^{68,69}$ In vitro, GB binds with high affinity to all the bronchial muscarinic receptors but has four- to fivefold higher selectivity for human $M_{1}$ and $M_{3}$ receptors than for the human $M_{2}$ receptor (equilibrium binding affinity constants of 9.60-9.81 and 9.47-9.64 vs 8.70-9.25). ${ }^{6,70}$ GB has also different dissociation kinetics for the three muscarinic receptors, with dissociation half-life of 11.4 and 13.9 for $\mathrm{M}_{3}$ and $\mathrm{M}_{1}$, respectively, vs $1.07 \mathrm{~min}$ for $\mathrm{M}_{2}$ and kinetic off rate of 0.061 and 0.05 vs 0.646 per minute, respectively. ${ }^{62,66} \mathrm{~GB}$ showed greater equilibrium binding selectivity $\left(\mathrm{M}_{3}\right.$ selectivity ratio [ratio of the affinity constant for the $M_{3}$ receptor vs that for the $M_{2}$ receptor] of 7.76-fold vs 2.09-fold) and kinetic selectivity ( $\mathrm{M}_{3}$ kinetic selectivity ratio [ratio of the area under the simulated association and dissociation curves for the $\mathrm{M}_{3}$ receptor vs that for the $M_{2}$ receptor] of 11.41-fold vs 4.30-fold) for $M_{3}$ versus $\mathrm{M}_{2}$ than tiotropium bromide, indicating the potential for an improved therapeutic index. ${ }^{62,66}$

Selective $M_{1}$ and $M_{3}$ receptors' blockers such as tiotropium and GB are therefore preferable to nonselective 
muscarinic antagonists, such as atropine and ipratropium bromide, which express their effects also on the $\mathrm{M}_{2}$ receptor subtype. ${ }^{68,71}$ Both GB and tiotropium are in fact selective for $M_{1}$ and $M_{3}$ receptors and have a similar duration of action with slow dissociation for these receptor subtypes. ${ }^{72}$ The slow dissociation profile of GB contributes to the long duration of action seen in clinical studies. ${ }^{73}$ Accordingly, GB rapidly dissociates from $\mathrm{M}_{2}$ receptors, thus avoiding their prolonged presynaptic blockade and reducing the antagonizing effect of acetylcholine release. ${ }^{72,74}$

Compared to tiotropium bromide, GB has a faster onset of action both in vitro and in vivo animal models. ${ }^{70}$ In fact, GB has shown to have both lower equilibrium binding affinity constants and a faster kinetic off rate (9.59 and 0.061 vs 10.37 and 0.015 per minute, respectively), which justifies its faster onset of action also in patients with moderate-to-severe COPD when compared with tiotropium bromide at a dosage of $18 \mu \mathrm{g} .{ }^{75}$ The onset of action, however, appeared slower both in terms of relief from airflow obstruction and in reduction of static hyperinflation when compared with aclidinium bromide $400 \mu \mathrm{g}$ in a double-blind cross-over study in severe and very severe patients with COPD. ${ }^{76}$

GB has been shown to be more potent than ipratropium bromide and tiotropium bromide in terms of concentration drug necessary to inhibit the contractile bronchial smooth muscle response by $50 \%{ }^{77}$ In a recent report that compared in vivo and in vitro effects of GB-DPI, aclidinium bromide DPI, and tiotropium bromide DPI, GB-DPI resulted to be the most potent of the three LAMAs investigated, inducing, with aclidinium, a faster bronchodilation compared to tiotropium. ${ }^{78}$ However, given the fact that so far, the approved marketed doses are not isoeffective for the two LAMAs, to make precise pharmacodynamics speculations of their effect in vivo remains a difficult task. A potential disadvantage brought by the GB fixed-dose combinations currently available on the market is represented by the GB dosage ( $\leq 50 \mu \mathrm{g})$; in fact, from the analysis of the forced expiratory volume in the first second $\left(\mathrm{FEV}_{1}\right)$ dose-response in pharmacodynamic studies, the optimal dose of GB appeared to be at least $100 \mu \mathrm{g}$, to be reflected in a $\mathrm{FEV}_{1}$ difference of $>100 \mathrm{~mL} .^{11}$

\section{Glycopyrrolate-approved formulations}

GB has been initially approved by the European Medicines Agency $^{79}$ and the Pharmaceuticals and Medical Devices Agency $^{80}$ in 2012 and by the FDA ${ }^{81}$ in 2015, as a standalone treatment for COPD as a dry-powder inhalation formulation. Subsequently, while in Europe it has been approved with OD posology, FDA approved its usage as BID long-acting bronchodilator both as a standalone treatment and as a fixeddose DPI combination with indacaterol. An MDI formulation containing a fixed-dose combination of GB and formoterol fumarate has been available in USA and Japan since 2016. A DPI formulation containing a triple combination of GB, formoterol fumarate, and beclomethasone has been approved for marketing in EU in May 2017. ${ }^{82}$

At the time of the present review, a nebulized formulation of GB is awaiting approval from FDA as a maintenance treatment for patients with COPD. ${ }^{83}$

\section{Efficacy studies}

Phase II and Phase III efficacy and safety clinical trials involving GBn are summarized in Table 2.

\section{Phase II studies}

GBn was studied in a Phase II, two-center, randomized, placebo-controlled, double-blind, dose ranging, single-dose, six-way cross-over trial in 35 patients with moderate-tosevere COPD (GOLD II/III), aged $40-75$ years. ${ }^{41}$ All patients were required to have at least $12 \%$ and $150 \mathrm{~mL}$ reversibility to inhaled ipratropium bromide as inclusion criteria. Eligible patients were randomized to receive a single dose of $\mathrm{GBn}$ via eFlow ${ }^{\circledR}$ nebulizer $(12.5,25,50,100$, and $200 \mu \mathrm{g})$ or placebo in six treatment visits separated by washout periods of 5-12 days; each dose was followed by an onset of response on placebo-adjusted $\mathrm{FEV}_{1}$ in $<5$ minutes $(60,80,100,130$, and $140 \mathrm{~mL}$ ). The bronchodilating effect progressively decreased over 24 hours period with a dose-response relationship, so that the higher the initial dose, the longer the duration of bronchodilation. The placebo-adjusted $\mathrm{FEV}_{1}$ improvement at $24 \mathrm{~h}$ postdose was $>100 \mathrm{~mL}$ with both the $100 \mu \mathrm{g}(104 \mathrm{~mL}$ increase over placebo effect) and $200 \mu \mathrm{g}(118 \mathrm{~mL}$ increase) doses; only the latter doses produced a significant improvement over placebo. ${ }^{41}$

The eFlow ${ }^{\circledR}$ was able to deliver all doses of GBn in $<2$ minutes (range 1.6-1.9 minutes). GBn peak plasma concentrations were measured within 15-30 minutes. ${ }^{41}$

The GOLDEN-1 study was a Phase II, multicenter, randomized, double-blind, placebo-controlled, four-period, incomplete block, cross-over study. ${ }^{42}$ The primary outcomes were the mean change in 24-hour postdose trough $\mathrm{FEV}_{1}$, and the standardized change in $\mathrm{FEV}_{1}$ area under the curve (AUC) (0-12 and 12-24 hours) on days 1 and 7. ${ }^{42}$ Secondary outcome measures were peak $\mathrm{FEV}_{1}$ (maximum $\mathrm{FEV}_{1}$ during the first 4 hours postdose on days 1 and 7); time to onset of action (time necessary to obtain a $\geq 10 \%$ improvement in postdose $\mathrm{FEV}_{1}$ ); treatment responders (proportion of subjects 


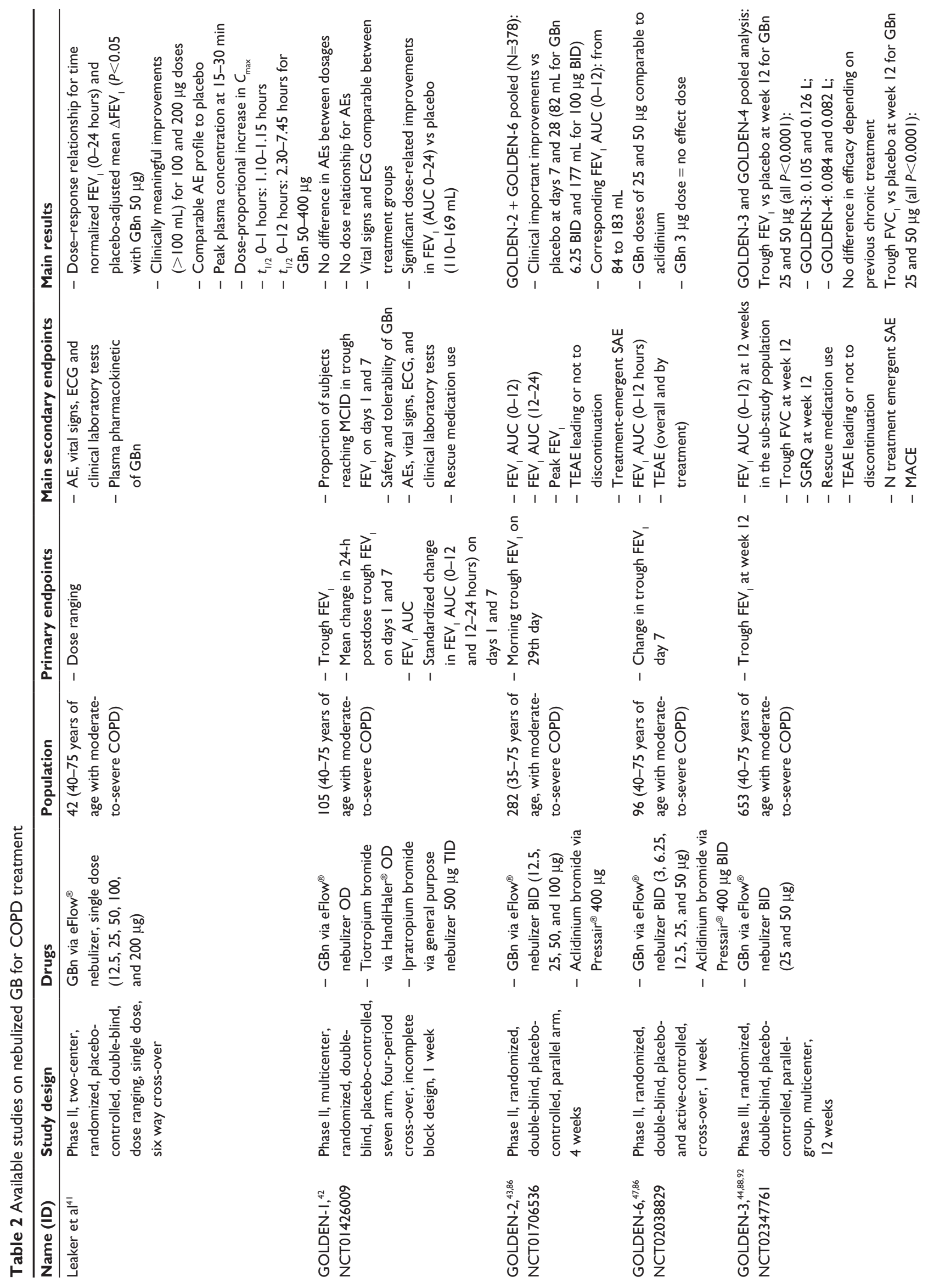




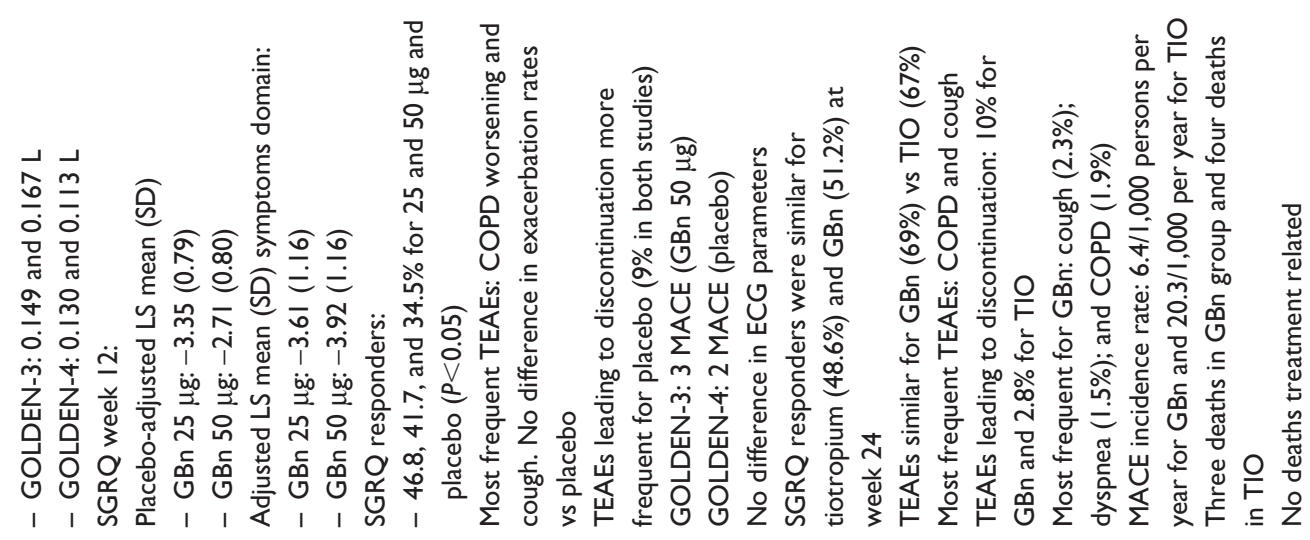

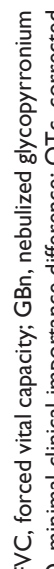
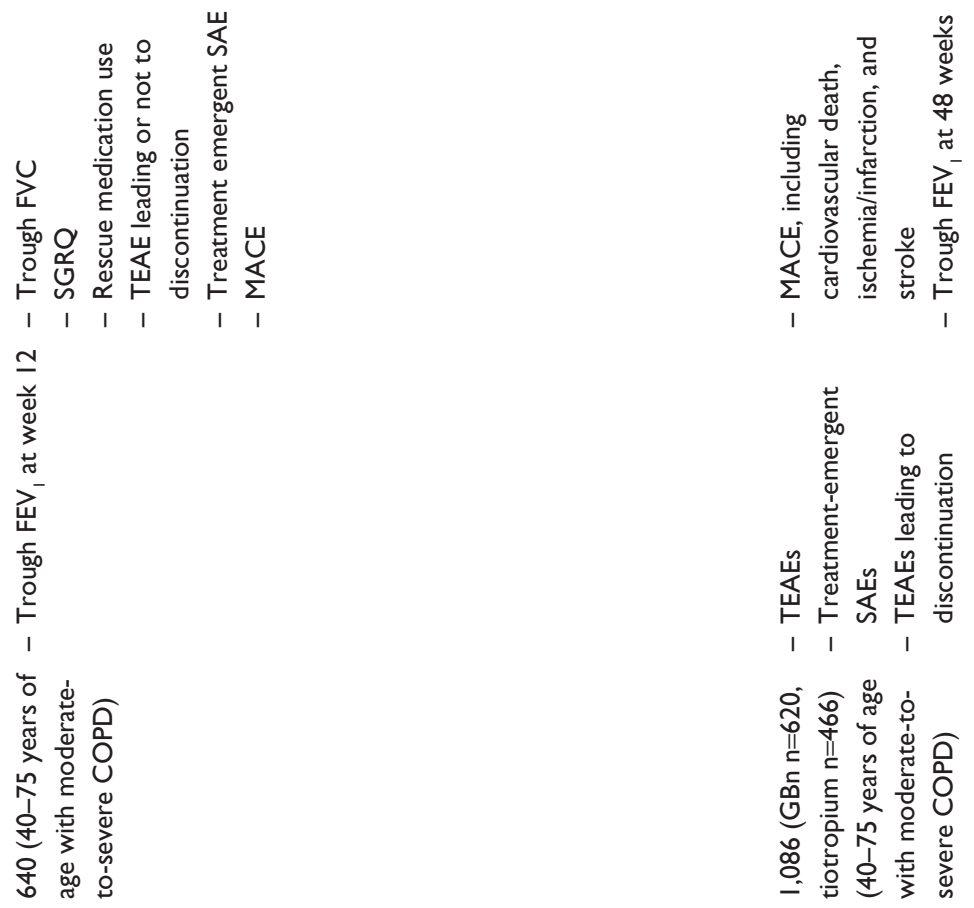

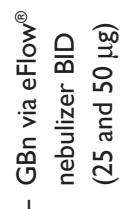
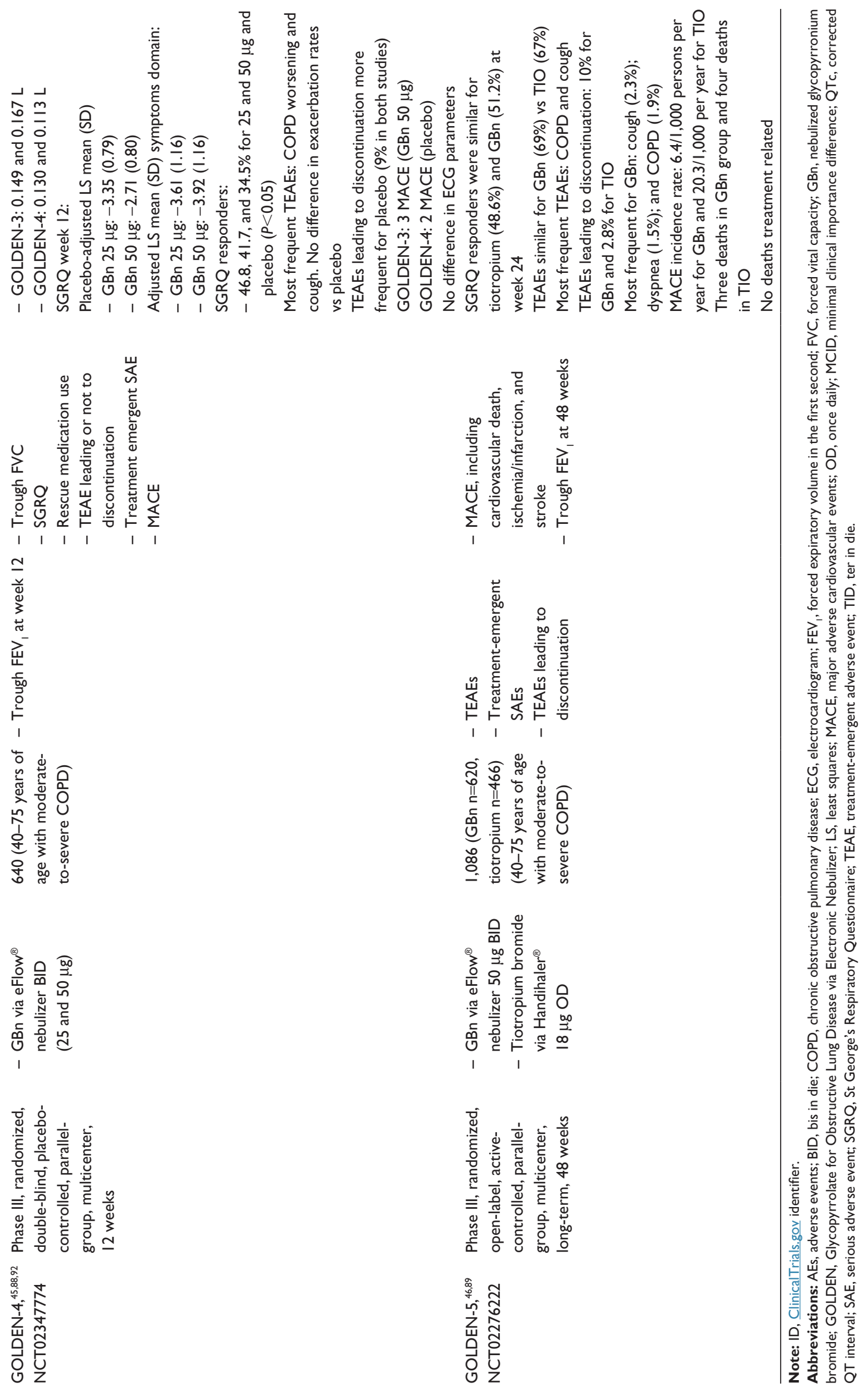
with clinically meaningful change from predose in trough $\mathrm{FEV}_{1}$ on days 1 and 7); and safety and tolerability. ${ }^{42}$

A total of 140 patients with moderate-to-severe COPD were randomized to four of seven treatments: GBn (25, 50,100 , and $200 \mu \mathrm{g}$ ) or placebo OD via eFlow ${ }^{\circledR}$ nebulizer, open-label tiotropium $18 \mu \mathrm{g}$ OD and open-label ipratropium $500 \mu \mathrm{g}$ three times a day delivered via jet nebulizer. All doses of GBn demonstrated dose-related and significant improvements in $\mathrm{FEV}_{1}$ AUC (0-24 hours) on day 7 compared to placebo, with estimated differences between GBn doses and placebo ranging between 110 and $169 \mathrm{~mL}^{.84}$

Following the pharmacokinetic profile of GBn, in the subsequent Phase II studies, only the BID posology has been maintained.

Two randomized, double-blind, placebo- and activecontrolled Phase II studies, GOLDEN-2 ${ }^{43,85}$ and GOLDEN-6, ${ }^{47}$ further characterized the efficacy of GBn in terms of doseresponse relationship recruiting a total of 378 patients with moderate-to-severe COPD (GOLDEN-2, N=282; GOLDEN-6, N=96). The GOLDEN-2 study had a parallel group design of 28 days, while the GOLDEN-6 was a 7-day crossover trial. It should be underlined that for the GOLDEN-2 study eligible patients were $<40$ years old. ${ }^{47}$

The primary endpoint of both studies was the change from baseline in trough $\mathrm{FEV}_{1}$ on day 7 or day 28 . Safety and tolerability were evaluated based on the incidence of treatmentemergent adverse events (TEAEs), serious AEs (SAEs), and discontinuations due to TEAEs. FEV ${ }_{1}$ AUC 0-12 was a secondary endpoint. The data were pooled for the lung function assessments, common to both studies..$^{31,47}$

In both studies, increasing doses of GBn (3-100 $\mu \mathrm{g}$ BID via $\mathrm{eFlow}^{\circledR} \mathrm{CS}$ nebulizer) were compared with placebo or aclidinium bromide $400 \mu$ g BID (Tudorza ${ }^{\circledR}$ Pressair $^{\circledR}$ ). GBn produced rapid onset ( $\leq 5$ minutes) dose-related bronchodilation following a single-dose administration. Improvements were maintained over a 24-hour period at all doses $>50 \mu \mathrm{g} .{ }^{41,47}$ The primary endpoints of both studies were reached obtaining on days 7 and 28 a significant improvement of the placebo-adjusted trough $\mathrm{FEV}_{1}$, with dose-related improvements ranging from $82 \mathrm{~mL}$ for the $6.25 \mu \mathrm{g}$ dose to $177 \mathrm{~mL}$ for $100 \mu \mathrm{g} \mathrm{BID}$, with corresponding changes in $\mathrm{FEV}_{1}$ $\mathrm{AUC}_{0-12}$, ranging from 84 to $183 \mathrm{~mL}$. The improvements in lung function for the 25 and $50 \mu \mathrm{g}$ BID doses were comparable to those obtained with aclidinium bromide (trough $\mathrm{FEV}_{1}=157 \mathrm{~mL}, \mathrm{FEV}_{1} \mathrm{AUC}_{0-12}=190 \mathrm{~mL}$ ). The GBn dose of $3 \mu \mathrm{g}$ BID was identified as the "no-effect" dose. .3,46,86 $^{-1}$

The GOLDEN-2 and GOLDEN-6 dose-finding studies supported the selection of GBn 25 and $50 \mu \mathrm{g}$ BID doses to advance in the subsequent Phase III GOLDEN trials. ${ }^{43,45,86}$

\section{Phase III studies}

GOLDEN- $3^{44}$ and GOLDEN- $4{ }^{45}$ were twin Phase III, 12 weeks, randomized, double-blind, placebo-controlled, parallelgroup, multicenter, efficacy, and safety trials.

The primary endpoint was change from baseline at week 12 in trough $\mathrm{FEV}_{1}$. Key secondary endpoints included forced vital capacity (FVC), St George's Respiratory Questionnaire (SGRQ), and rescue medication use. Safety was also assessed throughout the study.

Included patients were $40-75$ years old, with a $\geq 10$ packyear smoking history and a moderate-to-very-severe COPD (postbronchodilator $\mathrm{FEV}_{1}<80 \%$ of predicted normal or $\mathrm{FEV}_{1}$ / FVC ratio $<0.70$ ). To include a closer-to-real-life COPD population, patients with maintenance treatment with LABA (31\%) and ICS (29\%) and co-existing cardiovascular disease were not excluded in both studies; patients were stratified by cardiovascular history, $64 \%$ being at high risk. ${ }^{87}$ The administration of both doses of GBn/eFlow ${ }^{\circledR}$ (25 and $50 \mu \mathrm{g}$ BID) resulted in statistically and clinically significant improvements compared to baseline in placebo-adjusted trough $\mathrm{FEV}_{1}$ (GOLDEN-3: +105 and $+126 \mathrm{~mL} ; P \leq 0.0001$; GOLDEN-4: +84 and $+82 \mathrm{~mL} ; P \leq 0.0001)$ and placebo-adjusted trough FVC (GOLDEN-3: +149 and $+167 \mathrm{~mL}, P<0.001$; GOLDEN-4: +130 and $+113 \mathrm{~mL}, P<0.01)$ at week $12 .{ }^{87,88}$

GOLDEN-5 study was a Phase III, randomized, openlabel, active-controlled, parallel-group, multicenter, longterm safety trial of 48 weeks of treatment with GBn delivered by the $\mathrm{eFlow}^{\circledR} \mathrm{CS}$ system or tiotropium $18 \mu \mathrm{g}$ OD in 1,087 moderate-to-very-severe COPD patients. ${ }^{46}$ The population included patients with background use of LABA and history of significant cardiovascular disease. ${ }^{46}$

The primary endpoints were the incidence of TEAEs, SAEs, and discontinuations due to TEAEs. Secondary endpoints included patient-reported outcomes, rescue medication use, and the mean change from baseline over 48 weeks in trough $\mathrm{FEV}_{1}$. Lung function results confirmed the findings from GOLDEN-3 and -4 studies. Considering patients with and without background LABA therapy, improvements in trough $\mathrm{FEV}_{1}$ after GBn administration were not different, 99 and $105 \mathrm{~mL}$, respectively. ${ }^{46,89}$

GOLDEN-7 is a Phase I randomized, open-label, singledose per dosing period, five-way cross-over study in subjects aged 40-70 years with a diagnosis of moderate-to-severe COPD designed to evaluate the total systemic exposure and lung bioavailability of GBn compared to GB delivered by Breezhaler $^{\circledR}\left(\right.$ Seebri $\left.^{\circledR}\right)$. GB was administered with and without activated charcoal. Unfortunately to date, no results are available for this study, as the available abstracts have been withdrawn. ${ }^{47,90}$ 


\section{Safety and tolerability}

During the Phase II trial conducted by Leaker et al, single doses of GBn were well tolerated with AE profiles comparable to placebo. After all dosages, there were no clinically relevant changes in vital signs and ECG parameters, including QTc, and no typical muscarinic side effects, such as dry mouth and increased heart rate. ${ }^{41}$

In the GOLDEN-1, all doses of GBn were well tolerated with similar AE rates between placebo and $\mathrm{GBn}(31.2,29.7$, $26.9,35.5$, and $30.7 \%$ for placebo, 25, 50, 100, and $200 \mu \mathrm{g}$, respectively). There was no apparent dose-response relationship for incidence and severity of AEs. Mean changes in vital signs and ECG parameters from baseline to day 7 were comparable between the treatment groups ${ }^{41}$ No clinically significant differences compared to placebo were observed in terms of heart rate, blood pressure, and ECG parameters. ${ }^{42}$ The GBn safety profile was similar to placebo, tiotropium, and ipratropium in regard to cardiovascular AEs. ${ }^{91}$

GBn was well tolerated in GOLDEN-3 and -4 trials, with a combined overall incidence of TEAEs being numerically lower with GBn 25 and $50 \mu \mathrm{g}$ BID doses compared to placebo $(43.4,50.7$, and $52.3 \%$ for GBn 25 and $50 \mu \mathrm{g}$ doses and placebo, respectively). The most frequent AEs were represented by skin injury, headache, acute COPD exacerbations, cough, and dyspnea. Discontinuations due to TEAEs were numerically higher in the placebo group. There was one cardiovascular-related death in the $50 \mu \mathrm{g}$ BID group. ${ }^{88}$

A safety analysis of the 48 week GOLDEN-5 trial, in which the primary objectives were the number and percentage of patients with TEAE, demonstrated comparable and consistent results with GOLDEN-3 and GOLDEN-4 trials at 12 weeks. ${ }^{46,89}$ Discontinuation rate was $10 \%$ for GBn and $2.8 \%$ in patients receiving tiotropium; the most frequent TEAEs leading to discontinuation for GBn were cough (2.3\%), dyspnea (1.5\%), and COPD (1.9\%). The incidence rate of major adverse cardiovascular events (MACE) was 6.4 per thousand person-years for GBn and 20.3 for tiotropium. ${ }^{89}$ There were seven deaths during the study, none of which were considered treatment related: three in the GBn group $(0.5 \%)$ and four in the tiotropium group $(0.9 \%){ }^{89}$ Results from GOLDEN-5 trial, focused on long-term safety of GBn compared to placebo, showed that GBn BID was well tolerated, with a similar overall incidence of adverse events compared to the standard of care ( $48.6 \%$ for patients treated with $\mathrm{GBn}$ and $51.2 \%$ for tiotropium) ${ }^{89}$ Compared to tiotropium, the incidence of MACE was lower in the GBn group, although not significantly different compared to patients treated with tiotropium $(6.4 / 1,000$ persons per year for GBn and 20.3/1,000 per year for tiotropium), finding consistent with results from the GOLDEN-2 trial. ${ }^{85}$ The pooled analysis of GOLDEN-3 and -4 trials demonstrated a very low incidence of anticholinergic-related events such as dry mouth, with an incidence ranging between 0.5 and $2.3 \%$ in patients treated with GBn; only one gastrointestinal obstruction was reported in both studies, while glaucoma-related adverse events were very rarely observed $(0.5$ and $0.2 \%$ for GBn 25 and $50 \mu \mathrm{g}$ doses, respectively) ${ }^{88}$ As for urinary tract adverse events, urinary tract infection was reported in 2.3 and $1.9 \%$ for the GBn $25 \mu \mathrm{g}$ dose and 3.2 and $2.3 \%$ for the highest dose across the GOLDEN-3 and -4 trials, respectively. Urinary retention was not observed throughout the studies.

\section{Quality of life, patient satisfaction, and acceptability}

Pooled data including respiratory symptoms from GOLDEN-3 and -4 studies (1,293 patients in total) and data from the long-term trial GOLDEN-5 (1,086 patients) were analyzed. Patients had the same inclusion criteria across all trials. ${ }^{87-89}$

Clinically meaningful changes ( $\leq 4.0$ unit reduction) in SGRQ scores at week 12 were observed in 46.8, 41.7, and $34.5 \%$ of patients treated with GBn 25 and $50 \mu \mathrm{g}$ BID dosages and placebo, respectively. Improvements were largely driven by changes in the SGRQ symptom domain. ${ }^{87}$ During GOLDEN-5, administration of GBn 25 and $50 \mu \mathrm{g}$ BID resulted in statistically significant improvements from baseline in health-related quality of life, using the Evaluating Respiratory Symptoms in COPD (E-RS ${ }^{\mathrm{TM}}$ : COPD) electronic diary. E-RSTM: COPD total score was collected starting from week $2(P<0.05$ vs placebo for both doses), with no significant effect on rescue medication use. E-RS responders at week 12 were $48.1,40.3$, and $36.9 \%$ of patients in the GBn $25 \mu \mathrm{g}, 50 \mu \mathrm{g}$, and placebo groups, respectively; the placebo group scored -0.6 from the baseline while $\mathrm{GBn}-1.76$ and -1.52 for doses of 25 and $50 \mu \mathrm{g}$, respectively. In GOLDEN-5, improvements in E-RS total scores were seen across all visits in the GBn and tiotropium groups, with similar changes in the score (from -1.30 to -1.86 on the baseline score at week 12 and -1.5 for both tiotropium and GBn at week 48). ${ }^{92}$

A survey conducted among patients participating in the GOLDEN-5 study, which collected 473 questionnaires about patient-reported satisfaction with the investigational nebulizer and the ability to use it, suggested that regardless of previous nebulizer use, $75 \%$ of patients were "satisfied" or "very satisfied" with the novel delivery system. A total of $83 \%$ of patients also reported being "confident" to "very confident" that the study drug was being efficiently delivered to their lungs by the eFlow ${ }^{\circledR}$ CS nebulizer. Additionally, $>70 \%$ of 
the patients also rated the investigational nebulizer as "easy" or "very easy" to assemble, operate and clean. ${ }^{93}$

\section{Conclusion and place in therapy}

The number of elderly patients with COPD will increase as we become more efficient treating the disease and their chronic morbidities. It is not uncommon during everyday clinical practice to be unable to prescribe an adequate inhalation therapy for an elderly COPD patient due to his inability to handle the device or his low adherence to the suggested treatment. Treatment options that do not require coordination for activation and inhalation or necessitate an inspiratory peak flow threshold to be activated should represent the best treatment option for these patients. Nebulizers seem to fulfill that missing spot, although no nebulized bronchodilators are currently available for the treatment of stable COPD. The use of high efficiency nebulizers may bring together the highest number of advantages and the lowest number of disadvantages in terms of treatment efficacy and tolerability. GBn might be the first nebulized LAMA to be approved for use in COPD patients. The eFlow ${ }^{\circledR} \mathrm{CS}$ nebulizer has also some limits that should be considered: it is expensive and its maintenance may be complicated due to the need of cleaning the device after each administration. The latter aspect should not be forgotten, especially in patients that may be a priori selected for their inability to handle properly traditional inhalation devices.

The pathophysiology and functional impairment in patients with COPD guides the current technology dedicated to bronchodilator delivery, which should strive to assure the best efficiency of drug deposition within the lung, obtained with the lowest chance of critical errors possible. Nebulized glycopyrronium may represent the starting point of an alternative tool to increase the efficiency of long term bronchodilator therapy, especially in patients who present issues with the employment of devices containing predosed drugs.

\section{Author contributions}

All authors contributed toward data analysis, drafting and critically revising the paper and agree to be accountable for all aspects of the work.

\section{Disclosure}

PS has received financial support for research from Pfizer, Almirall, Chiesi Farmaceutici, and AirLiquide. He has received honoraria for lectures at national meetings from
Chiesi Farmaceutici, Novartis, Zambon Italia, AstraZeneca, Almirall, GlaxoSmithKline, Boehringer Ingelheim, Menarini, and Malesci-Guidotti. He has served as consultant for Zambon Italia, AstraZeneca, Novartis, Chiesi Farmaceutici, and Boehringer Ingelheim. DR has received honoraria for lectures from Astra Zeneca and Boehringer Ingelheim. AC, VV, and MR report no conflicts of interest in this work.

\section{References}

1. Global Initiative for Chronic Obstructive Lung Disease (GOLD) [homepage on the Internet]. Global Strategy for Diagnosis, Management, and Prevention of COPD. 2016. Available from: http:// goldcopd.org/. Accessed August 25, 2017.

2. Mathers CD, Loncar D. Projections of global mortality and burden of disease from 2002 to 2030. PLoS Med. 2006;3(11):e442.

3. McDonough JE, Yuan R, Suzuki M, et al. Small-airway obstruction and emphysema in chronic obstructive pulmonary disease. $N$ Engl J Med. 2011;365(17):1567-1575.

4. Senior R, Atkinson J. Chronic obstructive pulmonary disease: epidemiology pathophysiology, and pathogenesis. In: Alfred Fishman M, editor. Fishman's Pulmonary Diseases and Disorders. Vol. I. 4th ed. New York, NY: McGraw Hill Medical; 2008:707-728.

5. O'Donnell DE, Laveneziana P. Physiology and consequences of lung hyperinflation in COPD. Eur Respir Rev. 2006;15(100):61-67.

6. Pecchiari M, Radovanovic D, Santus P, D'Angelo E. Airway occlusion assessed by single breath N2 test and lung P-V curve in healthy subjects and COPD patients. Respir Physiol Neurobiol. 2016;234:60-68.

7. Santus P, Radovanovic D, Di Marco S, et al. Effect of indacaterol on lung deflation improves cardiac performance in hyperinflated COPD patients: an interventional, randomized, double-blind clinical trial. Int J Chron Obstruct Pulmon Dis. 2015;10:1917-1923.

8. Pecchiari MM, Santus P, Radovanovic D, D'Angelo EG. The acute effects of long acting bronchodilators on small airways detected in COPD patients by single breath $\mathrm{N} 2$ test and lung P-V curve. J Appl Physiol. Epub 2017.

9. O'Donnell DE, Fluge T, Gerken F, et al. Effects of tiotropium on lung hyperinflation, dyspnoea and exercise tolerance in COPD. Eur Respir J. 2004;23(6):832-840.

10. Scichilone N, Benfante A, Bocchino M, et al. Which factors affect the choice of the inhaler in chronic obstructive respiratory diseases? Pulm Pharmacol Ther. 2015;31:63-67.

11. Dolovich MB, Ahrens RC, Hess DR, et al; American College of Chest Physicians; American College of Asthma, Allergy, and Immunology. Device selection and outcomes of aerosol therapy: evidence-based guidelines: American College of Chest Physicians/American College of Asthma, Allergy, and Immunology. Chest. 2005;127(1):335-371.

12. Barta SK, Crawford A, Roberts CM. Survey of patients'views of domiciliary nebulizer treatment for chronic lung disease. Respir Med. 2002;96(6):375-381.

13. Santus P, Radovanovic D, Paggiaro P, et al. Why use long acting bronchodilators in chronic obstructive lung diseases? An extensive review on formoterol and salmeterol. Eur J Intern Med. 2015;26(6):379-384.

14. Hickey AJ, editor. Pharmaceutical Inhalation Aerosol Technology. 2nd ed. New York: Marcel Dekker; 2004.

15. Sabaté E. Adherence to Long-Term Therapies: Evidence for Action. Geneva: World Health Organization; 2003. Available from: http://www. who.int/chp/knowledge/publications/adherence_full_report.pdf?ua=1. Accessed August 18, 2017.

16. Sulaiman I, Cushen B, Greene G, et al. Objective assessment of adherence to inhalers by patients with chronic obstructive pulmonary disease. Am J Respir Crit Care Med. 2017;195(10):1407. 
17. Rau JL. Determinants of patient adherence to an aerosol regimen. Respir Care. 2005;50(10):1346-1359.

18. Ferroni E, Belleudi V, Cascini S, et al; OUTPUL Study Group. Role of tiotropium in reducing exacerbations of chronic obstructive pulmonary disease when combined with long-acting $\beta 2$-agonists and inhaled corticosteroids: the OUTPUL study. Pharmacoepidemiol Drug Saf. 2016;25(11):1295-1304.

19. Ram FS, Brocklebank DM, Muers M, Wright J, Jones PW. Pressurised metered-dose inhalers versus all other hand-held inhalers devices to deliver bronchodilators for chronic obstructive pulmonary disease. Cochrane Database Syst Rev. 2002;1:CD002170.

20. Turner MO, Patel A, Ginsburg S, FitzGerald JM. Bronchodilator delivery in acute airflow obstruction. A meta-analysis. Arch Intern Med. 1997;157(15):1736-1744.

21. Dhand R, Dolovich M, Chipps B, Myers TR, Restrepo R, Farrar JR. The role of nebulized therapy in the management of COPD: evidence and recommendations. COPD. 2012;9(1):58-72.

22. Wedzicha JA, Decramer M, Ficker JH, et al. Analysis of chronic obstructive pulmonary disease exacerbations with the dual bronchodilator QVA149 compared with glycopyrronium and tiotropium (SPARK): a randomised, double-blind, parallel-group study. Lancet Respir Med. 2013;1(3):199-209.

23. Sestini P, Cappiello V, Aliani M, et al; Associazione Italiana Pneumologi Ospedalieri Educational Group. Prescription bias and factors associated with improper use of inhalers. J Aerosol Med. 2006;19(2):127-136.

24. Blasi F, Canonica GW, Centanni S, et al. Genuair ${ }^{\circledR}$ usability test: results of a national public survey of the elderly. COPD. 2016;13(3):367-371.

25. Lavorini F, Mannini C, Chellini E, Fontana GA. Optimising inhaled pharmacotherapy for elderly patients with chronic obstructive pulmonary disease: the importance of delivery devices. Drugs Aging. 2016;33(7): $461-473$.

26. Crompton GK, Barnes PJ, Broeder M, et al; Aerosol Drug Management Improvement Team. The need to improve inhalation technique in Europe: a report from the Aerosol Drug Management Improvement Team. Respir Med. 2006;100(9):1479-1494.

27. Price D, Bosnic-Anticevic S, Briggs A, et al. Inhaler competence in asthma: common errors, barriers to use and recommended solutions. Respir Med. 2013;107(1):37-46.

28. Anderson P. Use of Respimat ${ }^{\circledR}$ Soft Mist ${ }^{\mathrm{TM}}$ Inhaler in COPD patients. Int J Chron Obstruct Pulmon Dis. 2006;1(3):251-259.

29. Rau JL. Practical problems with aerosol therapy in COPD. Respir Care. 2006;51(2):158-172.

30. Boe J, Dennis JH, O’Driscoll BR, et al; European Respiratory Society Task Force on the use of nebulizers. European Respiratory Society Guidelines on the use of nebulizers. Eur Respir J. 2001;18(1):228-242.

31. Sharafkhaneh A, Wolf RA, Goodnight S, Hanania NA, Make BJ, Tashkin DP. Perceptions and attitudes toward the use of nebulized therapy for COPD: patient and caregiver perspectives. COPD. 2013; 10(4):482-492.

32. Vogelmeier C, Hederer B, Glaab T, et al; POET-COPD Investigators. Tiotropium versus salmeterol for the prevention of exacerbations of COPD. N Engl J Med. 2011;364(12):1093-1103.

33. Decramer M, Chapman K, Dahl R, et al; INVIGORATE Investigators. Once-daily indacaterol versus tiotropium for patients with severe chronic obstructive pulmonary disease (INVIGORATE): a randomised, blinded, parallel-group study. Lancet Respir Med. 2013;1(7):524-533.

34. Buhl R, Banerji D. Profile of glycopyrronium for once-daily treatment of moderate-to-severe COPD. Int J Chron Obstruct Pulmon Dis. 2012;7:729-741.

35. Kerwin E, Hébert J, Gallagher N, et al. Efficacy and safety of NVA237 versus placebo and tiotropium in patients with COPD: the GLOW2 study. Eur Respir J. 2012;40(5):1106-1114.

36. Beeh KM, Singh D, Di Scala L, Drollmann A. Once-daily NVA237 improves exercise tolerance from the first dose in patients with COPD: the GLOW3 trial. Int J Chron Obstruct Pulmon Dis. 2012;7: 503-513.
37. Radovanovic D, Mantero M, Sferrazza Papa GF, et al. Formoterol fumarate + glycopyrrolate for the treatment of chronic obstructive pulmonary disease. Expert Rev Respir Med. 2016;10(10):1045-1055.

38. Vestbo J, Papi A, Corradi M, et al. Single inhaler extrafine triple therapy versus long-acting muscarinic antagonist therapy for chronic obstructive pulmonary disease (TRINITY): a double-blind, parallel group, randomised controlled trial. Lancet. 2017;389(10082): 1919-1929.

39. Johnson BE, Suratt PM, Gal TJ, Wilhoit SC. Effect of inhaled glycopyrrolate and atropine in asthma. Precipitated by exercise and cold air inhalation. Chest. 1984;85(3):325-328.

40. Cydulka RK, Emerman CL. Effects of combined treatment with glycopyrrolate and albuterol in acute exacerbation of chronic obstructive pulmonary disease. Ann Emerg Med. 1995;25(4):470-473.

41. Leaker BR, Barnes PJ, Jones CR, Tutuncu A, Singh D. Efficacy and safety of nebulized glycopyrrolate for administration using a high efficiency nebulizer in patients with chronic obstructive pulmonary disease. Br J Clin Pharmacol. 2015;79(3):492-500.

42. Sunovion Respiratory Development Inc. Study to investigate the dose response, safety and efficacy of nebulized ep-101(sun101) in patients with chronic obstructive pulmonary disease (COPD): GOLDEN-1 Study. Available from: https://clinicaltrials.gov/ct2/show/ NCT01426009?term=NCT01426009. NLM identifier: NCT01426009. Accessed July 15, 2017.

43. Sunovion Respiratory Development Inc. A study of the efficacy and safety of EP-101 (SUN101) in subjects with moderate to severe chronic obstructive pulmonary disease (GOLDEN-2). Available from: https:/clinicaltrials.gov/ct2/show/NCT01706536. NLM identifier: NCT01706536. Accessed July 15, 2017.

44. Sunovion Respiratory Development Inc. Efficacy and safety trial of 12 weeks of treatment with nebulized SUN-101 in patients with COPD (GOLDEN-3). Available from: https://clinicaltrials.gov/ct2/ show/NCT02347761. NLM identifier: NCT02347761. Accessed July 15, 2017.

45. Sunovion Respiratory Development Inc. Efficacy and safety trial of 12 weeks of treatment with nebulized SUN-101 in patients with COPD (GOLDEN-4). Available from: https://clinicaltrials.gov/ct2/ show/NCT02347774. NLM identifier: NCT02347774. Accessed July 15, 2017.

46. Sunovion Respiratory Development Inc. A long-term safety trial of treatment with nebulized SUN-101 in patients with COPD (GOLDEN-5). Available from: https://clinicaltrials.gov/ct2/show/NCT02276222. NLM identifier: NCT02276222. Accessed July 15, 2017.

47. Sunovion Respiratory Development Inc. A dose-range finding study of SUN-101 in subjects with moderate to severe COPD (GOLDEN 6). Available from: https://clinicaltrials.gov/ct2/show/NCT02038829. NLM identifier: NCT02038829. Accessed July 15, 2017.

48. Sunovion Respiratory Development Inc. Study to determine the amount of glycopyrrolate absorbed in the lungs after taking the medicine with a eFlow nebulizer and Seebri ${ }^{\circledR}$ Breezhaler $^{\circledR}$ with and without activated charcoal in subjects with moderate to severe chronic obstructive pulmonary disease (COPD) (GOLDEN7). Available from: https://clinicaltrials.gov/ct2/show/NCT02512302. NLM identifier: NCT02512302. Accessed July 15, 2017.

49. Berlinski A. Assessing new technologies in aerosol medicine: strengths and limitations. Respir Care. 2015;60(6):833-847.

50. Lenney W, Edenborough F, Kho P, Kovarik JM. Lung deposition of inhaled tobramycin with eFlow rapid/LC Plus jet nebulizer in healthy and cystic fibrosis subjects. J Cyst Fibros. 2011;10(1):9-14.

51. Ari A. Jet, ultrasonic, and mesh nebulizers: an evaluation of nebulizers for better clinical outcomes. Eurasian J Pulmonol. 2014;16(1):1-7.

52. Heyder J, Svartengren MU. Basic principles of particle behaviour in the human respiratory tract. In: Bisgaard H, O'Callaghan C, Smaldone GC, editors. Drug Delivery to the Lung. New York, NY: Marcel Dekker; 2002:21-45. 
53. de Boer AH, Gjaltema D, Hagedoorn P, Frijlink HW. Can "extrafine" dry powder inhalers improve lung deposition? Eur J Pharm Biopharm. 2015;96:143-151.

54. Pham S, Ferguson GT, Kerwin EM, Goodin T, Wheeler A, Bauer A. In-vitro characterization of the Eflow ${ }^{\circledR}$ Closed-System (eFlow ${ }^{\circledR} \mathrm{Cs}$ ) nebulizer with glycopyrrolate inhalation solution (SUN-101). Am J Respir Crit Care Med. 2017;195:A5472.

55. Merkus PJ, van Essen-Zandvliet EE, Parlevliet E, et al. Changes of nebulizer output over the years. Eur Respir J. 1992;5(4):488-491.

56. Alvine GF, Rodgers P, Fitzsimmons KM, Ahrens RC. Disposable jet nebulizers: how reliable are they? Chest. 1992;101(2):316-319.

57. O'Callaghan C, Barry PW. The science of nebulised drug delivery. Thorax. 1997;52(suppl 2):S31-S44.

58. Banfi P, Ticozzi N, Lax A, Guidugli GA, Nicolini A, Silani V. A review of options for treating sialorrhea in amyotrophic lateral sclerosis. Respir Care. 2015;60(3):446-454.

59. Blissit KT, Tillery E, Latham C, Pacheco-Perez J. Glycopyrrolate for treatment of clozapine-induced sialorrhea in adults. Am J Health Syst Pharm. 2014;71(15):1282-1287.

60. Robinul ${ }^{\circledR}$ (Glycopyrrolate) oral tablets [prescribing information]. Atlanta, GA: Shionogi Pharma; 2010.

61. National Center for Biotechnology Information [webpage on the Internet]. PubChem Compound Database; $C I D=11693$. 2017. Available from: https://pubchem.ncbi.nlm.nih.gov/compound/11693. Accessed July 25, 2017.

62. Carter NJ. Inhaled glycopyrronium bromide. A review of its use in patients with moderate to severe chronic obstructive pulmonary disease. Drugs. 2013;73(7):741-753.

63. Bevespi Aerosphere ${ }^{\mathrm{TM}}$ [prescribing information]. Wilmington: AstraZeneca Pharmaceuticals LP; 2017.

64. Ema.europa.eu. Seebri ${ }^{\circledR}$ Breezhaler $^{\circledR}$ (GB): European Medicines Agency Assessment Report. London, UK: European Medicines Agency; 2012. Available from: http://www.ema.europa.eu/docs/en_GB/ document_library/EPAR_-_Public_assessment_report/human/002430/ WC500133771.pdf. Accessed Jul 5, 2017.

65. Cazzola M, Page CP, Calzetta L, Matera MG. Pharmacology and therapeutics of bronchodilators. Pharmacol Rev. 2012;64(3):450-504.

66. Ulrik CS. Once-daily glycopyrronium bromide, a long-acting muscarinic antagonist, for chronic obstructive pulmonary disease: a systematic review of clinical benefit. Int J Chron Obstruct Pulmon Dis. 2012; 7:673-678.

67. Haddad EB, Patel H, Keeling JE, Yacoub MH, Barnes PJ, Belvisi MG. Pharmacological characterization of the muscarinic receptor antagonist, glycopyrrolate, in human and guinea-pig airways. Br J Pharmacol. 1999;127(2):413-420.

68. Restrepo RD. Use of inhaled anticholinergic agents in obstructive airway disease. Respir Care. 2007;52(7):833-851.

69. Moulton BC, Fryer AD. Muscarinic receptor antagonists, from folklore to pharmacology; finding drugs that actually work in asthma and COPD. Br J Pharmacol. 2011;163(1):44-52.

70. Sykes DA, Dowling MR, Leighton-Davies J, et al. The influence of receptor kinetics on the onset and duration of action and the therapeutic index of NVA237 and tiotropium. J Pharmacol Exp Ther. 2012;343(2): $520-528$.

71. Hansel TT, Barnes PJ. Tiotropium bromide: a novel once-daily anticholinergic bronchodilator for the treatment of COPD. Drugs Today (Barc). 2002;38(9):585-600.

72. Buels KS, Fryer AD. Muscarinic receptor antagonists: effects on pulmonary function. Handb Exp Pharmacol. 2012;208:317-341.

73. Hansel TT, Neighbour H, Erin EM, et al. Glycopyrrolate causes prolonged bronchoprotection and bronchodilation in patients with asthma. Chest. 2005;128(4):1974-1979.

74. Radovanovic D, Santus P, Blasi F, Mantero M. The evidence on tiotropium bromide in asthma: from the rationale to the bedside. Multidiscip Respir Med. 2017;12:12.

75. Verkindre C, Fukuchi Y, Flémale A, et al. Sustained 24-h efficacy of NVA237, a once-daily long-acting muscarinic antagonist, in COPD patients. Respir Med. 2010;104(10):1482-1489.
76. Santus P, Radovanovic D, Di Marco F, Raccanelli R, Valenti V, Centanni S. Faster reduction in hyperinflation and improvement in lung ventilation inhomogeneity promoted by aclidinium compared to glycopyrronium in severe stable COPD patients. A randomized crossover study. Pulm Pharmacol Ther. 2015;35:42-49.

77. Villetti G, Bergamaschi M, Bassani F, et al. Pharmacological assessment of the duration of action of glycopyrrolate vs tiotropium and ipratropium in guinea-pig and human airways. Br J Pharmacol. 2006;148(3): 291-298.

78. Rogliani P, Calzetta L, Ora J, et al. Pharmacological assessment of the onset of action of aclidinium and glycopyrronium versus tiotropium in COPD patients and human isolated bronchi. Eur J Pharmacol. 2015; 761:383-390.

79. Ema.europa.eu [webpage on the Internet]. London, UK: European Medicines Agency; 2017. Available from: http://www.ema.europa. eu/ema/index.jsp?curl=pages/medicines/human/medicines/002430/ human_med_001580.jsp\&mid=WC0b01ac058001d124. Accessed Oct 16, 2017.

80. Pmda.go.jp. JCN 301000500740. Tokyo, Japan: Pharmaceuticals and Medical Devices Agency; 2012. Available from: http://www.pmda. go.jp/files/000153897.pdf. Accessed Oct 15, 2017.

81. Accessdata.fda.gov [webpage on the Internet]. Administration. Silver Spring, MD: U.S. Food and Drug Administration; 2015. Available from: https://www.accessdata.fda.gov/scripts/cder/daf/ index.cfm? event $=$ overview.process $\& A p p 1 N_{0}=207923$. Accessed Oct 15, 2017.

82. Ema.europa.eu. Trimbow ${ }^{\circledR}$ Summary of Opinion (Initial Authorisation). London, UK: European Medicines Agency; 2017. Available from: http://www.ema.europa.eu/docs/en_GB/document_library/Summary_ of_opinion_-_Initial_authorisation/human/004257/WC500228080.pdf. Accessed Oct 11, 2017.

83. Sunovion.us. Marlborough, MA: Sunovion Press Release; 2017. Available from: http://www.sunovion.us/featured-news/pressreleases/20170526.pdf. Accessed on Oct 10, 2017.

84. Fogarty C, Kerwin E, Dunn K, Singh D, Tutuncu A. The GOLDEN-1 study: safety and bronchodilatory effects of nebulized glycopyrrolate (EP-101) using high efficiency nebulizer in patients with COPD. Eur Respir J. 2012;40:2194.

85. Tashkin DP. A review of nebulized drug delivery in COPD. Int J Chron Obstruct Pulmon Dis. 2016;11:2585-2596.

86. Donohue JF, Goodin T, Tosiello R, Wheeler A. Dose selection for SUN-101/eFlow ${ }^{\circledR}$ phase 3 clinical studies: results from GOLDEN (Glycopyrrolate for obstructive lung disease via electronic nebulizer) phase 2 dose-finding studies. Am J Respir Crit Care Med. 2017;195:A3591.

87. Ferguson GT, Kerwin EM, Donohue JF, Ozol-Godfrey A, Ganapathy V. Health-related quality of life (HRQoL) in moderate-to-very severe chronic obstructive pulmonary disease (COPD) patients treated with SUN-101 (glycopyrrolate/eFlow ${ }^{\circledR}$ ): findings from the phase 3 GOLDEN studies. Am J Respir Crit Care Med. 2017;195:A1402.

88. Kerwin EM, Donohue JF, Goodin T, et al. Efficacy and safety of glycopyrrolate/ $\mathrm{eFlow}^{\circledR}$ (nebulized glycopyrrolate) in moderate-to-very-severe COPD: Results from the glycopyrrolate for obstructive lung disease via electronic nebulizer (GOLDEN) 3 and 4 randomized controlled trials. Respir Res. 2017;18(1):8.

89. Ferguson GT, Goodin T, Tosiello R, Wheeler A, Kerwin EM. Long-term safety of SUN-101/eFlow ${ }^{\circledR}$ in moderate-to-very-severe COPD: results from the glycopyrrolate for obstructive lung disease via electronic nebulizer (GOLDEN) 5 study. Am J Respir Crit Care Med. 2017; 195:A3588.

90. Ali FY, Leaker BR, Nicholson GC, Singh D, Barnes PJ. A five-way crossover study to compare systemic absorption and bronchodilator effect of glycopyrrolate after a single dose delivered by nebulizer (SUN-101) or a dry powder inhaler (seebri) and in patients with COPD (GOLDEN-7). Am J Respir Crit Care Med. 2017;195:A3604.

91. Kerwin EM, Fogarty C, Dunn K, Singh D, Tutuncu A. Cardiovascular safety of nebulized glycopyrrolate (SUN-101) compared with tiotropium, ipratropium and placebo in patients with COPD. Am J Respir Crit Care Med. 2013;187:A1483. 
92. Donohue JF, Ferguson GT, Kerwin EM, Ozol-Godfrey A, Ganapathy V. Improvement in respiratory symptoms in moderate-to-very severe chronic obstructive pulmonary disease patients treated with SUN-101 (glycopyrrolate/eFlow ${ }^{\circledR}$ ) - patient-reported outcomes from the phase 3 GOLDEN studies. Am J Respir Crit Care Med. 2017;195:A5738.
93. Kerwin EM, Donohue JF, Ferguson GT, Ozol-Godfrey A, Ganapathy V. Patient device satisfaction with eFlow closed system nebulizer: results from the GOLDEN-5 study in patients with moderate-to-very-severe chronic obstructive pulmonary disease (COPD). Am J Respir Crit Care Med. 2017;195:A1416.

\section{Publish your work in this journal}

Drug Design, Development and Therapy is an international, peerreviewed open-access journal that spans the spectrum of drug design and development through to clinical applications. Clinical outcomes, patient safety, and programs for the development and effective, safe, and sustained use of medicines are the features of the journal, which has also been accepted for indexing on PubMed Central. The manuscript management system is completely online and includes a very quick and fair peer-review system, which is all easy to use. Visit http://www.dovepress.com/testimonials.php to read real quotes from published authors.

Submit your manuscript here: http://www.dovepress.com/drug-design-development-and-therapy-journal 